\title{
INTEGRACIÓN E INCORPORACIÓN DE LAS NORMAS INTERNACIONALES DE SOFT LAW SOBRE DERECHOS HUMANOS A LOS SISTEMAS PENAL Y DISCIPLINARIO EN COLOMBIA
}

\author{
Carlos Arturo Gómez Pavajeau* \\ Rafael Antonio López Iglesias**
}

\begin{abstract}
Resumen: Las normas de derecho blando no han sido consideradas como obligatorias, por no aparecer en tratados internacionales. Sin embargo, una interpretación que reconozca la dignidad humana y pretenda la ampliación del alcance de los derechos humanos permite que, a través del control de convencionalidad, dichas normas se integren al ordenamiento jurídico colombiano, por componer el Bloque de Constitucionalidad. Esta novedad ha sido
\end{abstract}

* Profesor Titular de Derecho Penal y Disciplinario de la Universidad Externado de Colombia. Cofundador y Consejero Académico del Instituto Colombiano de Derecho Disciplinario y de la Confederación Internacional de Derecho Disciplinario. Coordinador Académico de Barras de la Defensoría del Pueblo y Consultor de la Escuela Judicial "Rodrigo Lara Bonilla”. Bogotá D.C., Colombia. Correo-e: gomezpavajeau@hotmail.com

* Abogado de la Universidad Externado de Colombia. Especialista en Ciencias Penales y Criminológicas de la misma institución. Abogado Litigante. Bogotá D.C., Colombia. Correo-e: rafaellopeziglesias@ hotmail.com. Fecha de recepción: 11 de noviembre de 2016. Fecha de modificación: 16 de diciembre de 2016. Fecha de aceptación: 24 de febrero de 2017. Para citar el artículo: Carlos Arturo Gómez Pavajeau, Rafael Antonio LóPez Iglesias. "Integración e incorporación de las normas internacionales de soft law sobre derechos humanos a los sistemas penal y disciplinario en Colombia", en Revista Derecho Penal y Criminología, Vol. 37, n. ${ }^{\circ} 103$, julio-diciembre de 2016. Bogotá: Universidad Externado de Colombia, pp. 53-80, DOI: https://doi.org/10.18601/01210483.v37n103.04 
introducida por el Código Penitenciario y Carcelario, desde el cual las normas de derecho blando pueden incorporarse al Código Penal y de Procedimiento Penal; similar ejercicio cabría en el derecho disciplinario, debido a que el sistema penal es uno solo; al igual que el sistema disciplinario.

Palabras clave: sistema penal, sistema disciplinario, dignidad humana, derechos humanos, bloque de constitucionalidad, derecho blando, control de convencionalidad, integración.

\title{
INTEGRATION AND INCORPORATION OF THE INTERNATIONAL SOFT LAW REGULATIONS ON HUMAN RIGHTS TO CRIMINAL AND DISCIPLINARY SYSTEMS IN COLOMBIA.
}

\begin{abstract}
The soft law regulations have not been considered mandatory, because they do not appear on international treaties. However, an interpretation that acknowledges the human dignity and that pretends to amplify the scope of the human rights, allows that through the conventionality control, those regulations integrate to the Colombian law structure, since they compose the constitutionality block. This novelty has been introduced by the Penitentiary Code, from which, the soft law regulations can be incorporated to the Penal Code and the Penal Procedural Code; a similar exercise could be carried out with the disciplinary law, because the penal system is one; as the disciplinary system.
\end{abstract}

Keywords: penal system, disciplinary system, human dignity, human rights, constitutionality block, soft law, conventionality control, integration.

\section{INTRODUCCIÓN}

En Colombia, pese a la existencia de múltiples cuerpos normativos que abordan distintos asuntos penales (principalmente, el Código Penal -Ley 599 de 2000-, los Códigos de Procedimiento Penal -Ley 600 de 2000 y Ley 906 de 2004- y el Código Penitenciario y Carcelario -Ley 65 de 1993-, cada uno con sus respectivas modificaciones, además de otras normas), el sistema penal es uno solo ${ }^{1}$.

1 Siguiendo a Sandoval Huertas: "La misma pretensión de analizar un sistema penal, exige, seguidamente, que se indique qué se entiende por 'sistema penal', esto es, que se delimite el objeto de estudio". En consecuencia: "Con la expresión 'sistema penal' se hace referencia al conjunto de instituciones estatales y a sus actividades, que intervienen en la creación y aplicación de normas penales, concebidas estas en su sentido más extenso, valga decir, tanto disposiciones sustantivas como procedimentales y penitenciarias (o administrativas). Pero, además, hay que señalar que el análisis de dicho sistema debe tomar en consideración tanto su plano teórico, esto es, aquel en el cual está indicado cómo deben ser los procesos de creación y aplicación de las normas penales, como a su plano fáctico o práctico, es decir, cómo son tales procesos": SAndoval HuerTas, Emiro (1994). Sistema penal y criminología crítica. Santa Fe de Bogotá: Temis, pp. 5 y 6 -cursivas en el texto original-. 
También cabe predicar una idéntica cualidad del derecho disciplinario, compuesto principalmente por el Código Disciplinario Único -Ley 734 de 2002-, el Código General Disciplinario, el Código Disciplinario del Abogado -Ley 1123 de 2007- y los Códigos Disciplinarios de la Policía Nacional -Ley 1015 de 2006- y de las Fuerzas Armadas -Ley 836 de 2003-, así como sus normas complementarias, además de los estatutos disciplinarios de ciertas profesiones intervenidas.

La conceptualización del sistema penal colombiano como uno solo y la del sistema disciplinario con igual característica, está fundamentada en las siguientes razones:

1) Desde la perspectiva de la lógica: se trata de normas jurídicas que siguen la progresión que comienza con el establecimiento legal del delito o de la falta (tipificación); continúa con la determinación judicial de la existencia del crimen o de la falta, la atribución de responsabilidad penal o disciplinaria, y la imposición de la sanción (condena); y termina con el cumplimiento de la sanción correspondiente (ejecución).

2) Desde la perspectiva de la teoría del derecho: se trata de normas jurídicas mutuamente interrelacionadas, pues regulan comportamientos, actos, fenómenos y situaciones que están imbricadas entre sí. Argumento predicable tanto de las normas vinculadas al mundo penal, como de las normas atinentes a la órbita disciplinaria. Por ejemplo, el Código Penal regula la prescripción que es un asunto con impacto procesal y la pena que es un asunto con impacto penitenciario; el Código de Procedimiento Penal regula las garantías procesales que es un asunto con impacto sustancial y la detención preventiva que es un asunto con impacto penitenciario; el Código Penitenciario y Carcelario regula la privación de la libertad que es un asunto con impacto sustancial y la comparecencia al juicio del detenido preventivamente que es un asunto con impacto procesal.

3) Desde la perspectiva penal y disciplinaria: se trata de normas jurídicas que establecen, en conjunto, el ejercicio jurídico de la persecución delictiva y de la punición. O bien, de las normas jurídicas que fijan el ejercicio jurídico de la potestad disciplinaria.

Al examinar con cuidado cada código, puede encontrarse que empieza fijando los principios que tendrán la calidad de normas rectoras ${ }^{2}$. En este sentido, todas las normas rectoras pueden distribuirse dentro de dos grupos: i) aquellas normas que versan, exclusivamente, sobre las cuestiones restringidas al respectivo código; y, ii)

2 Sobre el valor de los principios y normas rectoras, consultar las sentencias de la Corte Constitucional, C-774 de 2001 y 775 de 2003, afirmándose en ésta que las normas o principios rectores "contienen postulados básicos, la filosofía y la orientación del sistema penal, y están destinadas a regir y guiar la interpretación y aplicación de las normas penales, de tal manera que los diversos desarrollos guarden plena coherencia con estos postulados". A la vez: Gómez Pavajeau, Carlos Arturo (2013). "Principios y normas rectoras" en Aspectos liberales y sociales del Derecho Penal. Bogotá: Ediciones Nueva Jurídica, pp. 55-82. 
aquellas normas que no se limitan únicamente al código, sino que por su operación, quedan entrelazadas con todos los componentes del sistema penal o con todos los componentes del sistema disciplinario.

Esta vicisitud o mejor aún, esta virtud, requiere ejemplificarse para una mejor ilustración.

Las normas rectoras de la antijuridicidad y de la culpabilidad pertenecen al derecho penal. Las normas rectoras de la defensa y de la lealtad, al derecho procesal penal. Las normas rectoras del sistema progresivo y de las obligaciones especiales para los jueces de penas y medidas de seguridad, al derecho penitenciario y carcelario. Empero, nótese que cada código contiene a lo largo del apartado, algunas normas rectoras que resultan comunes a los tres estatutos, verbigracia, la dignidad humana y la legalidad. Luego puede decirse que esta última categoría (el segundo de los grupos indicados) alude a normas rectoras que no solo imperan en el subsistema configurado con el código específico, sino que rigen en todo el sistema jurídico-penal, pues regulan supuestos semejantes, mediante cláusulas jurídicas similares.

Por consiguiente, estas normas rectoras se erigen en fundacionales de todo el sistema penal colombiano. Las normas rectoras a las cuales puede considerárseles como fundacionales son, entre otras, la dignidad humana, la integración, la legalidad, la libertad, la igualdad, los fines y las funciones de las penas, la defensa, el debido proceso, el derecho penal de acto y el principio de culpabilidad. Una consideración afín cabe hacer, con las debidas adaptaciones, de las normas rectoras en el derecho disciplinario.

En cuanto normas rectoras provienen de un similar fundamento jurídico, poseen un idéntico rango normativo y persiguen una finalidad análoga ${ }^{3}$. Entonces, las normas rectoras no pueden marginarse del análisis penal y disciplinario, dado su incuestionable raigambre constitucional, que cimenta y limita la juridicidad en los mencionados sistemas ${ }^{4}$.

3 "Si los principios rectores o normas rectoras -normas principios-del Código Penal derivan explícita o implícitamente de la Carta Política y de los Tratados Internacionales sobre Derechos Humanos (Bloque de Constitucionalidad), y los mismos se constituyen en la esencia y orientación del sistema penal, prevalecen sobre las demás y sirven de criterios para la interpretación (artículo 13 del Código Penal, 21 de la Ley 734 de 2002, 22 del Código General Disciplinario y 16 de la Ley 1123 de 2007), su rectoría o regencia tiene aplicación no solo respecto de las normas-reglas que los desarrollan, sino sobre todo el sistema penal (procesal penal, penitenciario carcelario, etc.) y el disciplinario, respectivamente": Gómez PAVAJEAU, CARlos ARTURo (2014). La lucha por los derechos en el derecho disciplinario. Bogotá: Ediciones Nueva Jurídica, p. 27 -cursivas en el texto original-.

4 "Si la Carta Política es norma de normas - norma que norma- y tiene aplicación inmediata como fuente del Derecho (artículos 4 y 85) y de su cuerpo hacen parte los tratados internacionales sobre Derechos Humanos por virtud del Bloque de Constitucionalidad (artículos 4 y 93), la interpretación de las disposiciones infraconstitucionales relacionadas con los sistemas penal y disciplinario debe 
Dentro de este trabajo tendrán una enorme importancia las normas rectoras de la dignidad humana y de la integración, ambas con asidero constitucional, además de fundacionales e imperantes en el sistema penal y en el sistema disciplinario, los cuales aluden a ellas con profusión ${ }^{5}$.

\section{BLOQUE DE CONSTITUCIONALIDAD}

El artículo 93 de la Carta Política incorpora al derecho interno, vía aprobación de las leyes respectivas, los tratados internacionales sobre Derechos y Deberes que hacen parte del Orden Público Internacional de los Derechos Humanos. A su vez, vía incorporación automática, se dispone el respeto por las reglas del Derecho Internacional Humanitario, según lo prevé el numeral 2 del artículo 214 ibídem.

El concierto axiológico de los Derechos Humanos está compuesto por aquellos que han sido reconocidos en los tratados, tal como se desprende del numeral 1 del artículo 2 del Pacto Internacional de Derechos Civiles y Políticos -los derechos reconocidos en el presente Pacto- y del numeral 1 del artículo 1 de la Convención Americana sobre Derechos Humanos -respetar los derechos y libertades reconocidas en ella-, lo cual evidentemente ratifica lo dispuesto en su Preámbulo, al referirse a derechos esenciales que requieren de un reforzamiento coadyuvante y/o complementario de naturaleza "convencional".

No obstante, uno y otro tratado de los arriba mencionados no se comprometen con limitar los derechos exclusiva y excluyentemente a los que hayan obtenido reconocimiento positivo o normativización, al establecer que los mismos no dependen de estatus normativos previos, sino de su derivación, de su inherencia, de la dignidad del ser humano y por su esencialidad, fundamentación anclada en los "atributos de la persona humana". Igual camino sigue la Constitución Política de Colombia, a través del artículo $94^{6}$.

respetar el contenido y sentido de aquel": Gómez Pavajeau, CARLos ARTURo. La lucha por los derechos en el derecho disciplinario, Op.cit. -cursivas en el texto original-.

5 En el sistema penal, la dignidad humana y la integración aparecen, respectivamente, en los artículos 1 y 2 de la Ley 599 de 2000, los artículos 1 y 2 de la Ley 600 de 2000, los artículos 1 y 3 de la Ley 906 de 2004, el artículo 5 de la Ley 65 de 1993, modificado por el artículo 4 de la Ley 1709 de 2014. Mientras que en el sistema disciplinario, la dignidad humana y la integración aparecen, respectivamente, en los artículos 8 y 21 de la Ley 734 de 2002, los artículos 1 y 16 de la Ley 1123 de 2007, los artículos 15 y 20 de la Ley 1015 de 2006, los artículos 6 y 13 de la Ley 836 de 2003.

6 El artículo 94 dispone que: "La enunciación de los derechos y garantías contenidos en la Constitución y en los convenios internacionales vigentes, no debe entenderse como negación de otros que, siendo inherentes a la persona humana, no figuren expresamente en ellos". 
Esos derechos reconocidos en el Pacto Internacional de Derechos Civiles y Políticos son un mínimo a cargo de los Estados Nacionales, quienes muy bien los pueden ampliar, por lo que es dable reconocer que su corpus iuris es de naturaleza abierta y no cerrada o de numerus clausus (numerales 1 y 2 del artículo 5).

Por supuesto, ello también se constata, incluso con un mayor alcance, por lo dispuesto en el artículo 29 de la Convención Americana sobre Derechos Humanos, en tanto ratifica el estándar mínimo de reconocimiento a cargo del Estado Nacional, pero con la advertencia de que si es superior el interno al externo, se aplica aquel (literal a $)^{7}$. De todos modos, de manera clara, el estándar internacional también debe ser el superior en dicho ámbito, identificable a partir de un examen de todas las convenciones suscritas por el Estado garante (literal b), a lo que se suman derechos no positivizados pero inherentes a la dignidad humana y a la forma democrática representativa de gobierno (literal c) o contenidos en declaraciones como la Americana de Derechos y Deberes del Hombre y "otros actos internacionales de la misma naturaleza" (literal d) ${ }^{8}$.

La jurisprudencia constitucional tiene dicho que "las disposiciones que hacen parte del Bloque de Constitucionalidad ostentan jerarquía constitucional por estar situadas a la altura de las normas del texto de la Carta y forman con él un conjunto normativo de igual rango", por lo que son "verdaderas fuentes del derecho" que:

Operan como disposiciones básicas que reflejan los valores y principios fundacionales del Estado y también regulan la producción de las demás normas del ordenamiento doméstico. Dado el rango constitucional que les confiere la Carta, las disposiciones que integran el bloque superior cumplen la cuádruple finalidad que les asigna Bobbio, a saber: i) servir de regla de interpretación respecto de las dudas que puedan suscitarse al momento de su aplicación; ii) la de integrar la normatividad cuando no exista norma directamente aplicable al caso; iii) la de orientar las funciones del operador jurídico, y iv) la de limitar la validez de las regulaciones subordinadas ${ }^{9}$.

El Orden Público Internacional de los Derechos Humanos irradia el entendimiento y la aplicación de los derechos y deberes fundamentales, dada su obligatoriedad que, aunada al carácter imperativo de la Constitución, exige que las restantes nor-

7 Así, con mayor extensión sobre el mejor estándar de garantías: Gómez PAVAJEAU, CARLos ARTURo. La lucha por los derechos en el derecho disciplinario, Op. cit., pp. 25 y 26 y 50-64, en especial, pp. 53 a 55.

8 Gómez Pavajeau, Carlos Arturo. La lucha por los derechos en el derecho disciplinario, Op. cit., pp. 60 y 61 .

9 Corte Constitucional. Sentencia C-067 de 2003, M.P.: Marco Gerardo Monroy CABra. Importantes antecedentes yacen en las sentencias C-531 de 1993, C-225 de 1995, T-483 y T-568 de 1999 y C-774 de 2001 . 
mas jurídicas, con rango inferior, cuando abordan derechos y deberes, se acoplen y respeten dicho Orden ${ }^{10}$.

Pero la incorporación al derecho interno colombiano de normas sobre Derechos Humanos de carácter internacional solo puede ser lograda por la aprobación de tratados internacionales o por incorporación automática, cuyo único ejemplo ha sido enunciado, con respecto a las normas del Derecho Internacional Humanitario.

Así se desprende de las sentencias C-067 de 2003 y C-291 de 2007, que dan cuenta de un concepto estricto de Bloque de Constitucionalidad, el cual tendría como parámetros para el juicio de constitucionalidad la Carta Política, los tratados internacionales sobre Derechos Humanos a que se refiere el artículo 93 de la Carta Política, los tratados sobre límites geográficos, el Convenio 169 de la Organización Internacional del Trabajo, los Convenios de Ginebra y el Protocolo II, y algunas leyes marco y estatutarias. El concepto amplio incluiría además la jurisprudencia de los tribunales internacionales, las declaraciones internacionales de Derechos y Deberes Humanos, las declaraciones efectuadas por el Comité de Derechos Humanos de la ONU y de la Corte y Comisión interamericanas de Derechos Humanos, a lo cual se sumarían, finalmente, las normas del soft law que propone la doctrina ${ }^{11}$.

Otras disposiciones normativas que hacen parte de instrumentos internacionales, pero que no adquieren la categoría jurídica de convenciones o tratados, podría decirse que en principio no hacen parte del Bloque de Constitucionalidad en sentido estricto y su rendimiento dogmático desde perspectivas sustanciales-materiales sería muy inseguro y diletante en el ámbito del concepto amplio.

De allí que, con toda razón, sería preferible utilizar el instrumento del "Bloque de Convencionalidad" como lo propone Hernández Castaño ${ }^{12}$. según Quinche Ramírez las ventajas son claras: i) La función del control de convencionalidad es de mayor espectro y riqueza sustancial que las funciones del Bloque de Constitucionalidad; ii) El Bloque de Constitucionalidad es una opción interpretativa y aplicativa, mientras que el control de convencionalidad es una obligación de todos los operadores

10 Gómez Pavajeau, Carlos Arturo. La lucha por los derechos en el derecho disciplinario, Op. cit., p. 25 .

11 Cfr. Quinche Ramírez, Manuel Fernando (2014). El Control de Convencionalidad. Bogotá: Editorial Temis, p. 147. Algunos afirman que la "existencia del bloque de constitucionalidad lato sensu permite integrar el soft law (...) como una herramienta de interpretación y progresividad para los derechos reconocidos en la Constitución Política": FAJARdo ArTURo, Luis Andrés (2016). "Estándares internacionales en materia de Justicia Transicional aplicables a Colombia" en CARLOS BERNAL Pulido, Gerardo Barbosa Castillo y Andrés Ciro Gómez (eds.). Justicia Transicional: el caso de Colombia. Bogotá: Universidad Externado de Colombia, p. 195.

12 Hernández Castaño, Diana PATRicia (2014). Le gitimidad democrática de la Corte Interamericana de Derechos Humanos en el control de convencionalidad. Bogotá: Universidad Externado de Colombia, pp. 95 y ss. 
jurídicos; iii) No existe claridad acerca de qué entra y qué no entra en el Bloque de Constitucionalidad, mientras que en el control de convencionalidad sí; y, iv) Las funciones del Bloque de Constitucionalidad son todas subordinadas, mientras que las del control de convencionalidad son normativas y plenas ${ }^{13}$.

Igual dificultad, en consecuencia, tienen para ser incorporadas por vía de normas rectoras o principios rectores, tal cual como sucede con los artículos 2 del Código Penal, 2 de la Ley 600 de 2000, 3 de la Ley 906 de 2004, 21 de la Ley 734 de 2002 y 16 de la Ley 1123 de 2007.

\section{LAS NORMAS DE SOFT LAW}

En términos generales, las normas de soft law (derecho suave o blando) han sido caracterizadas por la doctrina, como aquellas del ámbito internacional que no cuentan con la misma fortaleza que las normas de hard law (derecho duro). Por ejemplo, un tratado, un pacto o un convenio, serían normas de derecho duro; mientras que las recomendaciones, las pautas, los códigos de conducta o los principios, serían normas de derecho blando ${ }^{14}$.

Hay muchas disposiciones sobre derechos humanos aplicables a los procesos judiciales que figuran en instrumentos que no son tratados. A los instrumentos que no son tratados con frecuencia se los denomina declaraciones, principios, reglas, directrices, etc. La Declaración Universal de Derechos Humanos, el Conjunto de Principios para la Protección de Todas las Personas Sometidas a Cualquier Forma de Detención o Prisión y las Reglas Mínimas para el Tratamiento de los Reclusos son ejemplos de instrumentos que no son tratados en los que se establecen importantes garantías procesales. Los Estados no son formalmente partes en las normas que no son tratados. Si bien técnicamente carecen de los atributos legales que tienen los tratados, sí tienen la fuerza persuasiva de haber sido negociados por los Estados y de haber sido adoptados por órganos políticos, como la Asamblea General de la ONU, nor-

13 Cfr. Quinche RamíReZ, pp. 147-154.

14 El Diccionario Jurídico Espasa, define el soft law, así: "Una de las divisiones que hace la doctrina cuando habla de fuentes del Derecho comunitario es la de fuentes típicas (las previstas expresamente en los Tratados) y fuentes atípicas". Prosigue: "Entre estas destacan los actos que han venido colocándose bajo la expresiva denominación de soft law, concepto que aún no ofrece contornos precisos". Además: "Estos actos, que responden a nombres varios, y que pueden ser vinculantes o no, se caracterizan porque muy a menudo producen consecuencias jurídicas para sus destinatarios. En efecto, se trata de actos que, como las circulares interpretativas del Derecho nacional, expresan la posición del órgano competente -que no siempre es simplemente declarativa sino que en ocasiones innova o se autolimita- el cual solo se podrá separar de ella en sus decisiones concretas dirigidas a los particulares motivando suficientemente el interés público que lo justifica" (Diccionario Jurídico Espasa. Madrid, Espasa Calpe, 2001, p. 1337). 
malmente por consenso. A causa de esta fortaleza política se los considera autoritativos, y muchas resoluciones de tribunales nacionales y regionales de derechos humanos los citan y se fundamentan en ellos. Los instrumentos que no son tratados en ocasiones reafirman principios que ya son o se consideran legalmente vinculantes para todos los Estados conforme al derecho internacional consuetudinario ${ }^{15}$.

Dentro de las manifestaciones de soft law y en atención a los fines de este trabajo, interesan disposiciones normativas como principios, directrices, reglas, entre otras, que han sido expedidas por los órganos políticos de la ONU y de la OEA, pero que no han sido elevados a canon de convención o de tratado internacional.

Son expresión de la reciente y continua experiencia internacional y nacional en torno a la modificación del sistema de fuentes, aceptándose hoy uno de naturaleza abierta por el contrario de la naturaleza cerrada de los anteriores ${ }^{16}$.

Sin embargo, a pesar de que no son elevadas por los Estados Nacionales a normas aprobatorias de tratados internacionales sobre Derechos Humanos, tales instrumentos:

Han sido reconocidos como normas del derecho internacional consuetudinario, que es vinculante para todos los Estados (...). El derecho internacional consuetudinario es una fuente principal de obligaciones jurídicas internacionales vinculantes para todos los Estados, con independencia de las obligaciones que tengan contraídas en virtud de los tratados. Las normas del derecho internacional consuetudinario se derivan de "una práctica general aceptada como derecho"17.

Particularmente, unos entre muchos instrumentos internacionales del soft law se revelan como importantes, es el "Conjunto de Principios para la protección de todas las personas sometidas a cualquier forma de detención o prisión”, emitido por la Organización de Naciones Unidas, mediante Resolución 43/173 de 1988.

En la antedicha declaración, puede encontrarse que el quinto principio, en su numeral 1, establece la protección igualitaria ${ }^{18}$. Pero el mismo principio, en su numeral 2 , autoriza la realización de discriminación positiva ${ }^{19}$.

15 Amnistía Internacional. Juicios Justos. Manual de Amnistía Internacional. 2. ed., 2014, p.

16 Quinche RAMíreZ, Op.cit, pp. 163 y ss.

17 Amnistía Internacional, Op.cit, pp. 1 y 16.

18 "Los presentes principios se aplicarán a todas las personas en el territorio de un Estado, sin distinción alguna de raza, color, sexo, idioma, religión o creencia religiosa, opinión política o de otra índole, origen nacional, étnico o social, posición económica, nacimiento o cualquier otra condición".

19 "Las medidas que se apliquen con arreglo a la ley y que tiendan a proteger exclusivamente los derechos y la condición especial de la mujer, en particular de las mujeres embarazadas y las madres lactantes, los niños y los jóvenes, las personas de edad, los enfermos o los impedidos no se considerarán dis- 
Ahora bien, la mencionada declaración, al igual que otras normas del soft law relacionadas con las medidas de aseguramiento y las normas carcelarias y penitenciarias son objeto de integración al ordenamiento jurídico colombiano, dentro del cual tienen fuerza rectora sobre los fenómenos que aborda. Acerca de esta posibilidad no debe existir ninguna duda ${ }^{20}$. Las razones concretas para colegir su vigencia, son las siguientes:

1) El Bloque de Constitucionalidad: los principios hacen parte del Derecho Internacional de los Derechos Humanos, siendo materia jurídica susceptible de integración con las normas internas, lo cual resulta expresamente ordenado por los incisos 1 y 2 , del artículo 93 de la Constitución Política ${ }^{21}$. A la vez, por el artículo 2 de la Ley 599 de 2000, el artículo 2 de la Ley 600 de 2000 y el artículo 3 de la Ley 906 de $2004^{22}$.

Por el sistema disciplinario, los artículos 21 de la Ley 734 de 2002, 16 de la Ley 1123 de 2007, 13 de la Ley 836 de 2003 y 20 de la Ley 1015 de 2006.

De particular importancia, debe entenderse que todos esos principios, reglas, directrices y demás disposiciones son interpretaciones auténticas que se hacen por los órganos políticos de la ONU y de la OEA en torno a cómo deben ser entendidos los derechos y libertades, especialmente las garantías judiciales, consignados en el Pacto Internacional de Derechos Civiles y Políticos y en la Convención Americana sobre Derechos Humanos ${ }^{23}$.

Por ejemplo, para temas procesales vinculados con la privación de la libertad, el Comité de Derechos Humanos de la ONU se permitió efectuar la Observación General

criminatorias. La necesidad y la aplicación de tales medidas estarán siempre sujetas a revisión por un juez u otra autoridad".

20 Ley 65 de 1993, artículo 13: "Interpretación y aplicación del código. Los principios consagrados en este título constituyen el marco hermenéutico para la interpretación y aplicación del Código”.

21 El inciso primero del artículo 93 de la Constitución, dispone que: "Los tratados y convenios internacionales ratificados por el Congreso, que reconocen los derechos humanos y que prohíben su limitación en los estados de excepción, prevalecen en el orden interno". El inciso segundo, dispone que: "Los derechos y deberes consagrados en esta Carta, se interpretarán de conformidad con los tratados internacionales sobre derechos humanos ratificados por Colombia".

22 El artículo 2 de la Ley 599 de 2000 dispone que: "Las normas y postulados que sobre derechos humanos se encuentren consignados en la Constitución Política, en los tratados y convenios internacionales ratificados por Colombia harán parte integral de este código". El artículo 2 de la Ley 600 de 2000 dispone que: "En los procesos penales se aplicarán las normas que en materia de garantías se hallan consignadas en la Constitución Política y en los Tratados y Convenios internacionales ratificados por el Estado Colombiano". El artículo 3 de la Ley 906 de 2004 dispone que: "En la actuación prevalecerá lo establecido en los tratados y convenios internacionales ratificados por Colombia que traten sobre derechos humanos y que prohíban su limitación durante los estados de excepción, por formar Bloque de Constitucionalidad".

23 Sobre los "Instrumentos internacionales no convencionales": Gómez PAVAJEAu, CARLOS ARTURO. La lucha por los derechos en el derecho disciplinario, Op. cit., p. 73-75. 
13 al artículo 14 -del 13 de abril de 1984-del Pacto Internacional de Derechos Civiles y Políticos, ante las deficientes y contradictorias interpretaciones que se venían haciendo por parte de los Estados Nacionales de dicha disposición.

Por la similitud del fenómeno, puede citarse el artículo 25 del Código Civil, según el cual "la interpretación que se hace con autoridad para fijar el sentido de una ley oscura, de una manera general, solo corresponde al legislador".

Ciertamente, existen diferencias entre los fenómenos, allá se trata de normas internacionales y órganos políticos diferentes, no coincidentes con el Congreso de la República, empero, la ratio jurídica es la misma. El Código Civil habla de legislador y, en ese sentido, también lo sería el Presidente de la República cuando le corresponde legislar vía extraordinaria a través de los llamados decretos con fuerza de ley, actuando evidentemente como un intérprete político auténtico y genuino, en el evento en que decidiera dictar un decreto con fuerza de ley interpretativo de un acto anterior homólogo.

2) La dignidad humana: los principios se integran directamente con las normas internas, también con fundamento en el principio de la dignidad humana, el cual extiende su alcance sobre la Ley 599 de 2000, la Ley 600 de 2000, la Ley 906 de 2004 y la Ley 65 de 1993, modificada entre otras por la Ley 1709 de $2014^{24}$. Ello no solo por virtud de lo dispuesto en los Preámbulos del Pacto Internacional de Derechos Civiles y Políticos y la Convención Americana sobre Derechos Humanos, muy especialmente por la extensión temática normativa de su artículo 29, y consecuencialmente con lo dispuesto en torno a la dignidad humana en los Preámbulos de la Declaración Universal de los Derechos Humanos y de la Declaración Americana de los Derechos y Deberes del Hombre.

La expresión de los principios en el derecho Internacional de los Derechos Humanos no puede entenderse como mención exhaustiva, ya que su naturaleza básica no depende del contenido en la fuente formal original, sino de "contenido material y de la práctica internacional sobre los mismos", de manera que "la relación de principios está siempre abierta y puede ampliarse mediando el consensus necesario para ello", dice Manuel Díez ${ }^{25}$.

24 El artículo 1 de la Ley 599 de 2000 dispone que: "El derecho penal tendrá como fundamento el respeto a la dignidad humana". El artículo 1 de la Ley 600 de 2000 dispone que: "Todos los intervinientes en el proceso penal serán tratados con el respeto debido a la dignidad inherente al ser humano". El artículo 1 de la Ley 906 de 2004 dispone que: "Los intervinientes en el proceso penal serán tratados con el respeto debido a la dignidad humana”. El artículo 5 de la Ley 65 de 1993, modificado por el artículo 4 de la Ley 1709 de 2014, el cual en el primer inciso, dispone que: "En los establecimientos de reclusión prevalecerá el respeto a la dignidad humana, a las garantías constitucionales y a los Derechos Humanos universalmente reconocidos. Se prohíbe toda forma de violencia síquica, física o moral”. 
Si esas normas contenidas en el soft law son desarrollo de los derechos esenciales de la persona humana inherentes a su dignidad, resulta más que obvio que, cuando la normatividad internacional o nacional menciona la dignidad humana, también de aquellas implícitamente se está haciendo mención.

Como se puede ver, aquí no se está restringiendo el concepto, se está ampliando de manera compatible con el principio pro homine o pro libertate, aspecto totalmente compatible con la naturaleza de principio rector constitucional y legal que tienen los artículos 1 de la Carta Política y 1 del Código Penal frente a la totalidad del sistema penal, vía artículo 13 del último.

3) La superioridad de los derechos humanos: los derechos humanos prevalecen sobre cualquier otra categoría de derechos, en especial, cuando han sido aceptados con carácter universal. Estos derechos son establecidos por la comunidad de Estados, en normas de hard law como tratados y convenios, además de ser desarrollados mediantes normas de soft law como recomendaciones, pautas, códigos de conducta, principios, entre otras, según lo indica el inciso 1 del artículo 4 de la Ley 1709 de 2014, al remitir "a los Derechos Humanos universalmente reconocidos".

Dígase del artículo 4 de la Ley 1709 de 2014 que la norma rectora del artículo 5 de la Ley 65 de 1993 sufrió un importantísimo cambio, al incorporar a la materia relacionada con las medidas de aseguramiento y al Derecho Penitenciario y Carcelario, "los Derechos Humanos universalmente reconocidos".

Precisamente, las normas mencionadas permiten materializar la opinión de la doctrina autorizada en la materia, por ejemplo Fajardo Arturo señala que la importancia de las disposiciones del soft law estriba

Primordialmente en la capacidad de irradiar los derechos internos de los distintos Estados, que depende por supuesto del valor jurídico o interpretativo que cada jurisdicción decida darle. De allí que se erige como una de las herramientas más adecuadas para impulsar el desarrollo progresivo de los derechos humanos, y generar avances en los compromisos internacionales de los Estados sin las resistencias propias de la aceptación de obligaciones que implican los $\operatorname{tratados}^{26}$.

Esos derechos no son, salvo que se desprecie el efecto útil de las normas ${ }^{27}$, los que ya se encuentran enlistados en el derecho convencional o de los tratados, habida cuenta que sobraría la norma y se estaría rebajando el estatus-aunque ello sería por

26 FAJARdo Arturo, Op.cit, p. 195.

27 Sobre el efecto útil de las normas, consultar Corte Constitucional, sentencias T-001 de 1992 y C-600A de 1995. 
supuesto descartable con una correcta interpretación- que los mismos tienen por virtud de su consideración y pertenencia al Bloque de Constitucionalidad.

4) La interpretación vinculante: se repite que si bien los principios no han sido adoptados como convención o tratado, su existencia es una modalidad de interpretación auténtica del Pacto Internacional de Derechos Civiles y Políticos, efectuada por todos los Estados que conforman el órgano político de la ONU. Luego puede colegirse que es la interpretación patrocinada y aceptada por el Estado colombiano, en cuanto miembro de dicha organización internacional. Con base en ese mismo motivo, los jueces de la República se encuentran legitimados para acudir y aplicar el instrumento, directamente.

\section{5) La distinción conceptual y normativa entre la regulación de las limitaciones} y las ventajas: dentro de un Estado Social y Democrático de Derecho, siguiendo los postulados liberales sobre los cuales está edificado, las limitaciones a los derechos deben ser mínimas y estar señaladas con claridad, por el derecho positivo. En cambio, las ventajas incorporadas por las discriminaciones positivas o por cualquier otro medio, como formas para la realización de los derechos, no requieren tal ritualidad. Así lo establece el artículo 6 de la Ley 1709 de 2014, que introdujo el artículo 10A (sobre la intervención mínima) al Código Penitenciario y Carcelario, Ley 65 de $1993^{28}$.

Las ventajas, más no las restricciones, pueden estar comprendidas en el derecho duro, pero también en el derecho suave a nivel internacional como realmente sucede y nacional, pues los derechos humanos a nivel nacional pueden estar contenidos en "disposiciones legislativas o de otro carácter" como lo enseñan los artículos 2 numeral 2 del Pacto Internacional de Derechos Civiles y Políticos y 2 de la Convención Americana sobre Derechos Humanos.

6) La progresiva evolución de la jurisprudencia constitucional en torno a los instrumentos de soft law: la Corte Constitucional, en numerosas decisiones tanto de constitucionalidad como de tutela, ha valorado dentro de las consideraciones distintos instrumentos de derecho suave o blando. Con el simple propósito de ejemplificar, pueden identificarse distintas tendencias en cuanto al manejo que la jurisprudencia constitucional ha hecho del soft law.

Con respecto a las decisiones de constitucionalidad:

28 De conformidad con dicha norma: "El sistema penitenciario velará por el cumplimiento de los derechos y las garantías de los internos; los que solo podrán ser limitados según lo dispuesto en la Constitución, los tratados internacionales, las leyes y los reglamentos del régimen interno del Establecimiento Penitenciario y Carcelario". 
a) Aludir al concepto soft law y señalar sus cualidades, para caracterizar determinada figura jurídica como propia de aquel (C-160 de 2000).

b) No aludir al concepto soft law, pero discutir algún instrumento de este, para emplearlo como elemento interpretativo y lograr un análisis más completo, aunque sin referirse a su situación frente al Bloque de Constitucionalidad (C-564 de 1992, C-839 de 2001, C-228 de 2002, C-578 de 2002).

c) No aludir al concepto soft law, pero discutir algún instrumento de este, sin embargo, es expresamente negada su pertenencia al Bloque de Constitucionalidad (C-592 de 2005 , C-257 de 2008 -empero, el soft law es aludido y definido en uno de los salvamentos de voto-).

d) No aludir al concepto soft law, pero discutir algún instrumento de este, aunque es excluido de los componentes del Bloque de Constitucionalidad, aun cuando se estime que las normas demandadas también lo infringen (C-286 de 2014).

e) No aludir al concepto soft law, pero discutir instrumentos de este para efectuar el análisis, aunque sin referirse a la situación de alguno frente al Bloque de Constitucionalidad o sin decirlo expresamente, lo excluyen del mismo, pues queda limitado a la actividad interpretativa (C-579 de 2013, C-616 de 2014).

f) No aludir al concepto soft law, pero discutir algún instrumento de este, para lograr un análisis más completo, porque el contenido abordado por el instrumento es originario de tratados $\mathrm{u}$ otras normas internacionales acerca de derechos humanos que obligan al Estado, inclusive, pertenecientes al Bloque de Constitucionalidad, tornándose mandatorio dentro del ordenamiento jurídico, pues tal contenido también queda integrado al Bloque de Constitucionalidad, por ende, tiene capacidad vinculatoria y sirve como criterio para confrontar la constitucionalidad de las normas (C-203 de 2005, C-684 de 2009).

g) No aludir al concepto soft law, pero discutir algún instrumento de este para efectuar el análisis y examinar la constitucionalidad de las normas, porque unos hacen parte del Bloque de Constitucionalidad y otros hace parte del Bloque de Constitucionalidad lato, incluso el mismo instrumento puede encontrarse en uno u otro, dependiendo de la situación evaluada (C-715 de 2012).

h) Aludir al concepto soft law y reconocerle fuerza vinculante, por contener obligaciones del Estado frente a cierto asunto, empero, sin referirse a su situación frente al Bloque de Constitucionalidad (C-339 de 2014 -sentencia que, paradójicamente, examina la constitucionalidad de normas que establecen el reconocimiento del soft law-).

Con respecto a las decisiones de tutela: 
a) No aludir al concepto soft law, pero discutir instrumentos de este para el análisis (T-153 de 1998, T-804 de 2004, T-836 de 2014).

b) Aludir al concepto soft law y discutir instrumentos de este para el análisis (T-317 de 2006, T-235 de 2011, T-740 de 2011, T-513 de 2012, T-077 de 2013, T-295 de 2013).

c) Aludir al concepto soft law para el análisis, aunque sin incluir algún instrumento (T-781 de 2014).

Ahora bien, lo relevante es que para las decisiones de constitucionalidad o de tutela, el soft law o sus instrumentos, todavía no parecen, al menos por sí solos, contar con la fuerza necesaria para sustentar la decisión correspondiente (con la salvedad, sobre todo, aunque no necesariamente exclusiva, de las Reglas de Beijing). Luego haciendo un balance general, el desconocimiento de determinado instrumento de soft law permanece como obiter dicta y no como ratio decidendi, de nuevo, salvo alguna excepción. Sin embargo, desde cierto tiempo los instrumentos de soft law hacen parte, y cada vez más frecuente, de la evaluación jurídica, siendo esto, un paso adelante hacia la incorporación.

Además, según posiciones previas (C-225 de 1995 -que no alude al soft law o sus instrumentos, sino al carácter obligatorio del derecho internacional humanitario y el ius cogens, además de la integración automática y de la prelación de los tratados sobre derechos humanos-), parecería que el soft law o alguno de sus instrumentos no tendrían acogida a través de la integración al Bloque de Constitucionalidad. Empero, según las tendencias identificadas, podrían incorporarse, pues ya la Corte Constitucional lo ha hecho. En consecuencia, no parece que dicha corporación haya establecido una postura intransigente; por el contrario, se muestra bastante flexible, porque examina la cuestión de forma tal, que deja por el camino ciertos elementos para reevaluar su propia posición y si es imprescindible cambiar de parecer, adaptándose a las nuevas realidades, como lo hizo al evolucionar la calificación de los instrumentos de soft law desde meros criterios de interpretación, pasando por su aparición recurrente en los análisis, hasta aceptar la integración excepcional de determinados instrumentos al Bloque de Constitucionalidad y concederles fuerza vinculante.

Entonces, a raíz de la reforma incluida por la Ley 1709 de 2014, el Código Penitenciario y Carcelario permite la incorporación al mismo de las normas de soft law, erigiendo semejante posibilidad a la categoría de norma rectora. En consecuencia, los postulados de principios, reglas, directrices y demás disposiciones normativas -como el ejemplo tomado de la Resolución 43/173 de 1988 para significar la importancia del tema y su conexión con la Ley 1709 de 2014, que contemplan privilegios para determinados grupos específicos (mujeres, infantes, adolescentes, adultos mayores, individuos con padecimientos de salud o con discapacidades)- encuentran aplicación en Colombia, pues expanden el ámbito y el alcance de los derechos, siendo una posibilidad compatible con el favor rei o pro homine, porque se trata de derechos 
humanos que han sido aceptados con carácter universal, haciendo parte del artículo 4 de la antedicha ley.

Por ejemplo, ante la evidencia de la incorporación de ciertos derechos, no resulta atinado considerar que tales privilegios ya están previstos en el Código Penitenciario y Carcelario, por intermedio del "enfoque diferencial”, introducido por el artículo 2 de la Ley 1709 de 2014, que introdujo el artículo 3A, en la Ley 65 de $1993^{29}$.

La razón por la cual no coinciden, estriba en que el enfoque diferencial es un criterio para la ejecución de la sentencia, que permita el desarrollo de la resocialización ${ }^{30}$. Por su parte, los principio de la ONU, pretenden fijar principios para la protección del sentenciado, que eviten una innecesaria vulneración hacia sus derechos ${ }^{31}$.

En atención a que el sistema penal es uno solo, la instalación de los principios dentro del régimen penitenciario y carcelario, lleva a su necesaria interacción con el régimen penal sustancial y procesal, dentro de los cuales, también se inserta, puesto que el Código Penitenciario y Carcelario regula la detención preventiva, la cual, como privación de la libertad, es un fenómeno propio del derecho penal sustancial; y como medida cautelar personal, es un fenómeno propio del derecho penal adjetivo. Pero en cuanto implica mantener en reclusión al sujeto, recae en el

29 Al tenor del primer inciso de dicha norma: "El principio de enfoque diferencial reconoce que hay poblaciones con características particulares en razón de su edad, género, religión, identidad de género, orientación sexual, raza, etnia, situación de discapacidad y cualquiera otra. Por tal razón, las medidas penitenciarias contenidas en la presente ley, contarán con dicho enfoque”. Mientras que el segundo inciso indica: "El Gobierno Nacional establecerá especiales condiciones de reclusión para los procesados y condenados que hayan sido postulados por este para ser beneficiarios de la pena alternativa establecida por la Ley 975 de 2005 o que se hayan desmovilizado como consecuencia de un proceso de paz con el Gobierno Nacional".

30 La resocialización parece guardar mucha importancia para la Ley 65 de 1993, la cual establece la igualdad en el artículo 3, cuyo primer inciso señala: "Se prohíbe toda forma de discriminación por razones de sexo, raza, origen nacional o familiar, lengua, religión, opinión política o filosófica”. Pero el segundo inciso, trae la resocialización, así: "Lo anterior no obsta para que se puedan establecer distinciones razonables por motivos de seguridad, de resocialización y para el cumplimiento de la sentencia y de la política penitenciaria y carcelaria”. El artículo 9, también aborda la resocialización: "La pena tiene función protectora y preventiva, pero su fin fundamental es la resocialización. Las medidas de seguridad persiguen fines de curación, tutela y rehabilitación". A la vez, el artículo 10 aborda la resocialización: "El tratamiento penitenciario tiene la finalidad de alcanzar la resocialización del infractor de la ley penal, mediante el examen de su personalidad y a través de la disciplina, el trabajo, el estudio, la formación espiritual, la cultura, el deporte y la recreación, bajo un espíritu humano y solidario".

31 SANDOVAl Huertas había manifestado: "el personal penitenciario no solo puede imponer sanciones y en general controlar la vida de los reclusos sin sujeción a indicaciones legales precisas y taxativas, ni a trámites procesales mínimos que garanticen los derechos de los privados de libertad, ni a la revisión jurisdiccional de sus decisiones, sino que además -como lo anotábamos recientemente- sus actividades tienden a quedar ignoradas por la sociedad y, en suma, los reclusos se encuentran casi absolutamente desprotegidos ante cualesquiera determinaciones que en su respecto adopten los funcionarios de prisiones" (Sandoval HuerTas. Sistema penal, Op. cit., p. 95). 
espectro penitenciario y carcelario. A la vez, la integración está prevista para regir sobre todo el aparato penal del Estado; además, está prevista en todos los códigos, con superioridad ${ }^{32}$.

\section{CONTROL DE CONVENCIONALIDAD COMO INSTRUMENTO PARA EXIGIR INTERNAMENTE LA APLICACIÓN DE LAS NORMAS DEL SOFT LAW EN EL DERECHO COLOMBIANO}

Con respecto al control de convencionalidad, ha sido establecido que tiene fundamento en el control de los jueces sobre los compromisos internacionales, en el principio de supremacía del derecho convencional, en el principio pro homine y en el principio de efectividad de los Derechos Humanos ${ }^{33}$.

La Convención Americana sobre Derechos Humanos dispone, en su artículo 29, la forma y sustancialidad de la interpretación propia del Bloque de Constitucionalidad, en armonía con los artículos 4 y 93 de la Carta Política.

La doctrina señala, en el ámbito de estudio del Control de Convencionalidad, que el principio pro homine que se deriva del artículo 29 de la Convención Americana sobre Derechos Humanos ${ }^{34}$ es norma de ius $\operatorname{cogens}^{35}{ }^{36}$. La interpretación pro homine

32 El artículo 13 de la Ley 599 de 2000, dispone que: "Las normas rectoras contenidas en este Código constituyen la esencia y orientación del sistema penal. Prevalecen sobre las demás e informan su interpretación". El artículo 24 de la Ley 600 de 2000, dispone que: "Las normas rectoras son obligatorias y prevalecen sobre cualquier otra disposición de este código. Serán utilizadas como fundamento de interpretación". El artículo 26 de la Ley 906 de 2004, dispone que: "Las normas rectoras son obligatorias y prevalecen sobre cualquier otra disposición de este código. Serán utilizadas como fundamento de interpretación".

33 Quinche Ramírez, Manuel Fernando. El Control de Convencionalidad, Op. cit., pp. 108, 130 y ss.

34 Ampliamente Miranda Bonilla, HAIDEer (2016). Entre constitucionalidad y convencionalidad. Bogotá: Ediciones Nueva Jurídica, p.155.

35 Hernández Castaño, p. 87. También Quinche Ramírez, Op. cit., pp. 66, 67, 72 y ss.

36 Si se aceptare un muy buen criterio de la doctrina y la jurisprudencia constitucional, aun cuando aislada, como que el ius cogens hace parte del Bloque de Constitucionalidad, si las normas del soft law pertenecen al ius cogens también entraría a formar parte del Bloque de Constitucionalidad: Cfr. QuiNCHE RAMíREZ, Op. cit., p. 145.

Sobre las normas de ius cogens se tiene dicho: "El artículo 53 de la Convención de Viena sobre el Derecho de los Tratados la define como "una norma aceptada y reconocida por la comunidad internacional de Estados en su conjunto como norma que no admite acuerdo en contrario y que sólo puede ser modificada por una norma ulterior de derecho internacional general que tenga el mismo carácter". Las normas imperativas de derecho internacional se denominan también con la expresión latina jus cogens": Cfr Amnistía Internacional, Op. cit., p. 16. 
ha sido admitida tanto por la Corte Constitucional ${ }^{37}$ como por la Sala de Casación Penal de la Corte Suprema de Justicia ${ }^{38}$.

Todos los jueces de la República, sin excepción, tanto los pertenecientes al ámbito jurisdiccional como a otras formas sustanciales de administrar justicia como el Derecho Disciplinario o el Sancionador Administrativo, tienen la obligación oficiosa de ejercer sus facultades-deberes de jueces del control difuso de convencionalidad, en orden a la incorporación de los tratados sobre derechos humanos y su doctrina, así como la jurisprudencia de los tribunales internacionales, al "interior de los procesos judiciales", debe tomar plena consciencia de que "a mayor defensa de los derechos humanos en el ejercicio del control de convencionalidad, mayor el grado de legitimidad democrática de resultado", en tanto y cuanto, como se estableció en la Opinión Consultiva OC-6/86 de mayo 9 de 1986, Corte Interamericana de Derechos Humanos: "en la protección de los derechos humanos está necesariamente comprendida la noción de restricción al ejercicio del poder estatal” 39 .

Entonces, la realización del control de convencionalidad es imperativa para las autoridades públicas, sobre todo las judiciales (formales y materiales), pues de esta manera reivindican el Orden Público Internacional de los Derechos Humanos ${ }^{40}$. A su vez, el control de convencionalidad es forzoso ${ }^{41}$. Finalmente, la falta de aplicación del mismo, puede motivar la actuación de entidades internacionales para la protección de los derechos humanos ${ }^{42}$.

Por virtud del control difuso de convencionalidad todos los jueces de la República se convierten en "Jueces Interamericanos" 43 . En consecuencia:

37 Sentencia C-551 de 2003, M.P. Humberto Sierra Porto, Fundamento Jurídico n. ${ }^{\circ} 279$. Trascendental resulta el salvamento de voto del Magistrado Alberto Rojas Ríos a la Sentencia C-469 de 2016, cuyo criterio jurídico muy seguramente más temprano que tarde tendrá que ser admitido por la Corte Constitucional, pues demuestra cómo se vive de espalda al Orden Público Internacional de los Derechos Humanos, en tanto se viene propiciando "una discordancia entre la jurisprudencia constitucional y los estándares internacionales en materia de derechos humanos", con claro desconocimiento del principio pro homine, lo que demuestra la necesidad de activar el "control de convencionalidad difuso" que tienen los jueces nacionales, en orden a la aplicación de los mejores estándares de garantías al confrontarse los internacionales con los nacionales.

38 Sentencia de tutela de segunda instancia de julio 31 de 2007, radicación 31.972, M.P. MAURo SOLARTE PORTILla.

39 Para el efecto consultar HeRnÁndez CASTAÑo, Op.cit, pp. 39 y ss. Muy especialmente pp. 74, 78 y 96. También así, como una forma de "enfrentar la hostilidad del poder", Quinche RAMíREZ, Op. cit., p. 173

40 Gómez Pavajeau. La lucha por los derechos en el derecho disciplinario, Op. cit., p. 76.

41 Gómez Pavajeau. La lucha por los derechos en el derecho disciplinario, Op. cit., p. 76.

42 Gómez Pavajeau. La lucha por los derechos en el derecho disciplinario, Op. cit., p. 77.

43 Miranda Bonilla, Op.cit, pp. 130 y ss. Hernández Castaño, p. 87. También Quinche Ramírez, Op. cit., pp. 66, 67, 72 y ss. En materia penal consultar. Gómez Pavajeau, Carlos Arturo y Del 
Todos los jueces y tribunales deben aplicar la Convención Americana y por ello están llamados a ejercer el control difuso de convencionalidad; lo que implica que en caso de incompatibilidad o conflicto entre una norma interna que deban aplicar para resolver un caso concreto y normas de la Convención Americana deben dar preferencia a estas y desaplicar las normas de derecho interno contrarias a la Convención ${ }^{44}$.

Dentro de la búsqueda del mejor estándar es preciso el estudio comparativo entre los estándares internacionales y nacionales. En el juicio para la determinación del mejor estándar juegan, por supuesto, las normas constitucionales de los Estados Nacionales, pero también las leyes.

Así lo señala el literal b) del artículo 29 de la Convención, según el cual su articulado no será motivo para "limitar el goce y ejercicio de cualquier derecho o libertad que pueda estar reconocido de acuerdo con las leyes de cualquiera de los Estados Partes" (Resaltado fuera de texto).

Como se vio, la Ley 1709 de 2004 incorporó a la legislación interna colombiana los Derechos Humanos universalmente reconocidos que emanan del concepto de dignidad de la persona, esto es, los que resultan esenciales no contenidos explícita o directamente en las convenciones y tratados internacionales, pues ya estos lo estaban, sino las normas del soft law, de las cuales se discute su vinculatoriedad, pues si bien son instrumentos internacionales sobre derechos humanos, no han sido incorporadas por los Estados Partes a sus legislaciones internas.

Pero además, por virtud de la cláusula según la cual no se pueden excluir del ámbito de protección "otros derechos y garantías que son inherentes al ser humano" (literal c del artículo 29 de la Convención), por supuesto diferentes a los consignados en las convenciones y tratados, habida cuenta de que tal norma sobraría si fuera así, ya que no se trata de efectos de redundancia sino de amplificación de los derechos por virtud del principio hermenéutico del efecto útil de la norma, en el marco de una interpretación pro homine o pro libertate. Debe reconocerse que el artículo 4 de la Ley 1709 de 2014 plantea un fenómeno nuevo, antes desconocido, y un poco diferente al concepto de Bloque de Constitucionalidad, pero sin duda vinculado con su núcleo esencial.

Villar Delgado, Danilo (2014). Estándares Internacionales Vinculantes que Rigen la Detención Preventiva. Bogotá: Defensoría del Pueblo, pp. 45-47.

44 Brewer-Carías, Allan R. (2013). "El control de convencionalidad, con particular referencia a la garantía del derecho a la protección judicial mediante un recurso sencillo, rápido y efectivo de amparo de los derechos humanos", en Control de Convencionalidad y responsabilidad del Estado. Bogotá: Universidad Externado de Colombia, p. 63. También así Quinche RAmíREZ, Op. cit., pp. 54-79 y 109. 
La Carta de las Naciones Unidas en su Preámbulo enseña el valor indiscutible de la dignidad de las persona, puesto que reafirma "la fe en los derechos fundamentales del hombre, en la dignidad y en el valor de la persona humana" y el de "crear las condiciones bajo las cuales puedan mantenerse la justicia y el respeto a las obligaciones emanadas de los tratados y de otras fuentes del derecho internacional" (Resaltado fuera de texto), pues el concierto de naciones que la conforman persiguen el bien indiscutible de obrar de "conformidad con los principios de la justicia y del derecho internacional” (numeral 1 del artículo 1).

La justicia tiene como fundamento el reconocimiento de la dignidad intrínseca a todo ser humano y de sus derechos inalienables, la dignidad y el valor de la persona, elementos esenciales del progreso social y de la elevación del nivel de vida dentro de un "concepto más amplio de libertad", dice el Preámbulo de la Declaración Universal de los Derechos Humanos, por lo cual los Estados Miembros deben procurar asegurar "el respeto universal y efectivo de los derechos y libertades fundamentales del hombre", ya que su "desconocimiento y menosprecio han originado actos de barbarie ultrajantes para la conciencia de la humanidad", lo cual tiene como único remedio, según su artículo 1 , el reconocimiento de los derechos y la puesta en práctica de la idea según la cual "todos los seres humanos nacen libres e iguales en dignidad y derechos y, dotados como están de razón y conciencia, deben comportarse fraternalmente los unos con los otros".

Así también, de manera similar, se expresa la Declaración Americana de los Derechos y Deberes del Hombre, como se puede apreciar en su Preámbulo, en el cual, de una manera categórica, destaca que la "cultura es la máxima expresión social e histórica del espíritu”, poniéndose de presente cómo todos los Estados Partes del sistema deben propender y practicar una cultura jurídica basada en el reconocimiento de la dignidad de la persona y sus valores esenciales, los derechos inherentes a la misma y la capacidad del hombre de actuar de manera consciente y voluntaria en un ámbito de fraternidad con los demás.

En tal ámbito se mueven también los preámbulos del Pacto Internacional de Derechos Civiles y Políticos y la Convención Americana sobre Derechos Humanos, destacando la dignidad inherente al ser humano, los derechos que de la misma derivan en igualdad, e inalienables, para todos los miembros de la familia humana y los deberes mutuos que los asisten. Son los derechos esenciales del hombre fundados en la libertad personal y la justicia social.

El tema de la integración e incorporación del Orden Público Internacional de los Derechos Humanos no solo es asunto que interese al Bloque de Constitucionalidad, habida cuenta que debe reconocerse que allí también juega un papel importante la ley, toda vez que el artículo 30 de la Convención Americana permite que entre en juego tal nivel jerárquico, cuando de restricciones se trata, en tanto y cuanto: 
Las restricciones permitidas, de acuerdo con esta Convención, al goce y ejercicio de los derechos y libertades reconocidas en la misma, no pueden ser aplicadas sino conforme a leyes que se dictares por razones de interés general y con el propósito para el cual han sido establecidas.

Expresión significativa y moduladora de tal idea es el artículo 6 de la Ley 1709 de 2014, al consagrar un principio rector de cardinal importancia, tal como sucede con el de intervención mínima, al dar cuenta de que "el sistema penitenciario velará por el cumplimiento de los derechos y las garantías de los internos; los que solo podrán ser limitados según lo dispuesto en la Constitución, los tratados internacionales, las leyes y los reglamentos del régimen interno del Establecimiento Penitenciario y Carcelario".

Como se puede ver, las restricciones necesitan intervención normativa, la cual debe darse a través de mínimo la ley. El reglamento es únicamente para especificar, no puede crear ex novo prohibiciones, pues de lo contrario se estaría vaciando de contenido sustancial al principio de legalidad, contemplado en el artículo 1 de la ley, muy especialmente en su inciso 2 , que señala de manera absolutamente clara y perentoria que "nadie podrá ser sometido a pena, medida de seguridad, ni a un régimen de ejecución que no esté previsto en la ley vigente".

En tal norma se desarrolla un principio del Derecho Internacional de los Derechos Humanos, según el cual:

En el ejercicio de sus derechos y en el disfrute de sus libertades, toda persona estará solamente sujeta a las limitaciones establecidas por la ley con el único fin de asegurar el reconocimiento y el respeto de los derechos y libertades de los demás, y de satisfacer las justas exigencias de la moral, del orden público y del bienestar general en una sociedad democrática (numeral 2 del artículo 29 de la Declaración Universal de los Derechos del Hombre).

Así también lo disponen, de manera clara y perentoria, los artículos XXVIII y XXIX de la Declaración Americana de los Derechos y Deberes del Hombre.

Las normas del soft law son, como se puede apreciar por su contenido en el marco de un desarrollo cierto, eficaz y eficiente de las garantías, una expresión del principio de progresividad, como respuesta a las exigencias precisadas de la Carta de las Naciones Unidas y de la Declaración Universal de los Derechos Humanos, cuyo contenido jurídico es incuestionable a la luz de lo dispuesto en el literal d del artículo 29 de la Convención Americana sobre Derechos Humanos.

Con total firmeza debe aseverarse que, por virtud de lo expresado en el Considerando primero del Preámbulo de la Convención Americana sobre Derechos Humanos, puede inferirse la existencia, validez y exigibilidad de las normas del soft law, toda vez que 
se refiere a principios y derechos de los que se han ocupado las declaraciones, pero también de otros "desarrollados en otros instrumentos internacionales, tanto en el ámbito universal como regional", sin distinguir si son convencionales o expresiones de los órganos políticos de cada uno de los sistemas.

Por ello, en el marco regional, la Declaración Americana de los Derechos y Deberes del Hombre, por virtud de la dignificación y reconocimiento que se ha hecho de la persona humana, no se conforma con el aseguramiento y protección de los derechos esenciales del hombre expresa y explícitamente reconocidos, sino que cifra su futuro en la "creación de circunstancias que le permitan progresar espiritual y materialmente" al hombre americano. De allí que la "protección internacional de los derechos del hombre debe ser guía principalísima del derecho americano en evolución”, que debe fortalecerse cada vez más, entendiendo que es un punto de partida, un "sistema inicial de protección" conformado por los derechos de la declaración y "las garantías ofrecidas por el régimen interno de los Estados" (Considerandos).

La transversalidad penal, procesal penal, penitenciaria y carcelaria de la Ley 1709 de 2014 es evidente, basta una ojeada sin prevenciones de su articulado para percatarse el observador imparcial de tal aserto. Ello se constata muy especialmente en el inciso final del principio rector de la legalidad, de que da cuenta el artículo 1, según el cual "la detención preventiva de las personas que están siendo investigadas o juzgadas es excepcional"; no podría ser menos, pues el artículo 1 de la Ley 65 de 1993, que se refiere al contenido sustancial-material de la ley, expresa de manera inequívoca que "este Código regula el cumplimiento de las medidas de aseguramiento, la ejecución de las penas privativas de la libertad personal y de las medidas de seguridad".

También, para los efectos de la transversalidad de la Ley 65 de 1993, especialmente de sus principios rectores, basta mirar lo que sucede con el contenido de los artículos 7,8 y 11 , cuyo contenido también va referido a las medidas de aseguramiento y a las situaciones de captura.

La incorporación e integración de normas pro homine y pro libertate no demanda el rigor del desarrollo legal a detalle, como sí se deprende del artículo 6 respecto de restricciones a derechos, puesto que su técnica de desarrollo es la norma en blanco o el concepto jurídicamente indeterminado, eso sí, limitados por la regla según la cual, las "restricciones impuestas a las personas privadas de la libertad estarán limitadas a un estricto criterio de necesidad y deben ser proporcionales a los objetivos legítimos para los que se han impuesto" y "la carencia de recursos no podrá justificar que las condiciones de reclusión vulneren los derechos fundamentales de las personas privadas de la libertad", según lo enseña el artículo 4 de la Ley 1709 de 2014, modificatorio del artículo 5 de la Ley 65 de 1993. 
Así las cosas, haciendo parte la "ley” de los estándares de garantías que contiene el artículo 29 de la Convención Americana, lo dispuesto en ella, y sobre todo cuando se trata de derechos y garantías no consagrados en convenciones o tratados, pero inherentes a la dignidad humana, por virtud de lo estipulado en el artículo 4 de la Ley 1709 de 2014, las normas del soft law deben ser necesaria e inexorablemente consideradas en el control de convencionalidad.

De allí que, el control de convencionalidad que emana del artículo 29 de la Convención Americana debe considerarse como el instrumento a través del cual se reconocen los efectos del principio de progresión del derecho y el sistema americano en evolución.

La interpretación pro homine indica que "el contenido de los derechos humanos siempre tendrá que tener un carácter progresivo, y no regresivo", afirma Hernández Castaño, quien cita a Ayala Corao, para sostener que "la progresividad de los derechos humanos como principio interpretativo define la aplicación de la norma más favorable al individuo, independientemente del instrumento donde éstos se encuentren regulados. Sea en el derecho internacional o interno en una norma constitucional o legal" 45 .

La Corte Constitucional ha reconocido la aplicación del principio de progresividad en materias procesales: "todos los derechos fundamentales tienen contenidos prestacionales cuyo desarrollo está sujeto al principio de progresividad y no regresión” 46.

En consecuencia de lo anterior se afirma allí mismo:

Los derechos fundamentales tienen unos contenidos mínimos -negativos y positivos- de cumplimiento inmediato y otros de contenido abierto y sujetos a la configuración legislativa. Sin embargo, la libertad de configuración del legislador de dichos contenidos abiertos e indeterminados no es absoluta; el legislador está sujeto a los principios de no discriminación y progresividad y no regresividad-cuando se trata de contenidos prestacionales-, entre otros (Fundamento jurídico ${ }^{\circ}{ }^{\circ} 2.5 .2$ ).

Así las cosas, se sigue afirmando, que "el principio de progresividad y no regresión conlleva i) la obligación del Estado de ampliar la realización de todos los derechos fundamentales y ii) la proscripción de reducir los niveles de satisfacción actuales" (Fundamento Jurídico n. 2.5.4.), toda vez que "no hay razón para no extender el principio de progresividad y no regresión también a las facetas prestacionales de los derechos civiles y políticos" (Fundamento Jurídico n. ${ }^{\circ}$ 2.6.5). Así entonces, “desde el punto de vista normativo, el Estado debe introducir normas que extiendan la sa-

45 Hernández Castaño, Op.cit., pp. 80 y 81.

46 Corte Constitucional, Sentencia C-372 de 2011, M.P. Pretelt Chaljub. Fundamento jurídico n. ${ }^{\circ}$ 2.5. Reiterada por Sentencia C-875 de 2011, con ponencia del mismo magistrado. 
tisfacción de los derechos y debe abstenerse de modificar la normativa vigente para limitar, suprimir o restringir los derechos o garantías ya reconocidas" (Fundamento Jurídico n. ${ }^{\circ}$ 2.6.6), siendo claro que "aunque estas afirmaciones parecieran restringirse a los derechos sociales, lo cierto es que, como se indicó previamente, deben extenderse a cualquier faceta de desarrollo progresivo de un derecho fundamental" (Fundamento Jurídico n. ${ }^{\circ}$ 2.6.8).

Precisamente, si bien el instituto del control de convencionalidad no pertenece al sistema ONU, no es menos cierto que se encuentra dentro de sus propósitos objetivos, pues con él se crean condiciones "bajo las cuales pueden mantenerse la justicia y el respeto a las obligaciones emanadas de los tratados y de otras fuentes del derecho internacional" (Punto tercero del Preámbulo de la Carta de las Naciones Unidas), como serían, en nuestra propuesta, las normas del soft law. Precisamente, dicho marco, cabe en los "Propósitos y Principios" de la Carta de las Naciones Unidas, dentro de los que está, según su numeral 3 del artículo 1, el desarrollar y estimular el respeto a los derechos humanos de una forma integral, donde participen las organizaciones internacionales de derechos humanos y los Estados Partes y Miembros, de "conformidad con los principios de la justicia y del derecho internacional" (ibídem, numeral 1).

Ya en otra investigación fue señalado ${ }^{47}$ que la Corte Interamericana de Derechos Humanos viene diciendo:

El poder judicial debe ejercer una especie de control de convencionalidad entre las normas jurídicas internas que aplican en los casos concretos y la Convención Americana sobre Derechos Humanos. En esta tarea el poder judicial debe tener en cuenta no solamente el tratado, sino la interpretación que del mismo ha hecho la Corte Interamericana, intérprete última de la Convención Americana ${ }^{48}$.

Ese control de convencionalidad es obligatorio, especialmente cuando se alegan mejores garantías a partir del Orden Público Internacional de los Derechos $\mathrm{Hu}$ manos, toda vez que, como dice el órgano judicial de supervisión antes señalado, "cuando una cuestión ha sido resuelta definitivamente en el orden interno según las

47 Gómez Pavajeau, Carlos Arturo (2013). "Interpretación y aplicación de normas internacionales sobre Derechos Humanos en materias penal y disciplinaria”, en Revista Derecho Penal y Criminología, Vol. 34, n. 96, enero-junio de 2013. Bogotá: Universidad Externado de Colombia, pp. 211 y 212.

48 Corte Interamericana de Derechos Humanos, sentencia de noviembre 24 de 2006, Caso Trabajadores cesados del Congreso Vs Perú, párrafo 128. 
cláusulas de la Convención, no es necesaria traerla a esta Corte para su aprobación o confirmación ${ }^{49}$.

Así las cosas, la definición de un asunto por parte de los poderes públicos de los Estados Nacionales, incluyendo el poder judicial, deben atender el control de convencionalidad so pena de la intervención de los órganos de supervisión internacional sobre Derechos Humanos.

Se ha dicho recientemente 50

La responsabilidad estatal bajo la Convención solo puede ser exigida a nivel internacional después de que el Estado haya tenido la oportunidad de declarar la violación y reparar el daño ocasionado por sus propios medios. Esto se asienta en el principio de complementariedad (subsidiariedad), que informa transversalmente el Sistema Interamericano de Derechos Humanos, el cual es, tal como lo expresa el Preámbulo de la misma Convención Americana, "coadyuvante o complementario de la [protección] que ofrece el derecho interno de los Estados americanos".

De tal manera, el Estado

Es el principal garante de los derechos humanos de la personas, de manera que, si se produce un acto violatorio de dichos derechos, es el propio Estado quien tiene el deber de resolver el asunto a nivel interno y [en su caso] reparar, antes de tener que responder ante instancias internacionales como el Sistema Interamericano, lo cual deriva del carácter subsidiario que reviste el proceso internacional frente a los sistemas nacionales de garantías de los derechos humanos ${ }^{51}$.

Esas ideas también han adquirido forma en la jurisprudencia reciente bajo la concepción de que todas las autoridades y órganos de un Estado Parte en la Convención tienen la obligación de ejercer un "control de convencionalidad"52. Lo anterior signi-

49 Corte Interamericana de Derechos Humanos, sentencia de diciembre 6 de 2001, Caso Las Palmeras Vs Colombia, párrafo 33.

50 Corte Interamericana de Derechos Humanos, sentencia de noviembre 30 de 2012, Caso Masacre de Santo Domingo Vs Colombia.

51 Caso Acevedo Jaramillo y otros Vs. Perú. Interpretación de la Sentencia de Excepciones Preliminares, Fondo, Reparaciones y Costas. Sentencia del 24 de noviembre de 2006, párrafo 66.

52 Cuando un Estado es Parte de un tratado internacional como la Convención Americana, todos sus órganos, incluidos sus jueces, están sometidos a aquel, lo cual les obliga a velar por que los efectos de las disposiciones de la Convención no se vean mermados por la aplicación de normas contrarias a su objeto y fin, por lo que los jueces y órganos vinculados a la administración de justicia en todos los niveles están en la obligación de ejercer ex officio un "control de convencionalidad" entre las normas 
fica que se ha instaurado un control dinámico y complementario de las obligaciones convencionales de los Estados de respetar y garantizar derechos humanos, conjuntamente entre las autoridades internas (primariamente obligadas) y las instancias internacionales (en forma complementaria), de modo que los criterios de decisión puedan ser conformados y adecuados entre sí.

\section{CONCLUSIÓN}

Las normas de soft law internacional sobre Derechos Humanos, han sido incorporadas a la legislación nacional mediante el artículo 5 de la Ley 65 de 1993, modificado por el artículo 4 de la Ley 1709 de 2014, especialmente, en todo aquello que guarda relación con la materia tratada por la misma, esto es, medidas de aseguramiento y normas penitenciarias y carcelarias.

Su rango legal es evidente, pues se trata de una norma en blanco o, en la terminología constitucional moderna, un concepto jurídico indeterminado, pero determinable a través de las normas del soft law internacional de los Derechos Humanos.

No obstante, como tema vinculado con la dignidad del ser humano y los derechos inherentes a dicha condición, de conformidad con el sistema abierto de los derechos esenciales de la persona que emana de la Declaración Universal de los Derechos Humanos, de la Declaración Americana sobre Derechos y Deberes del Hombre, del Pacto Internacional de Derechos Civiles y Políticos, de la Convención Americana sobre Derechos Humanos, de los artículos 1, 2, 4, 29, 85, 93 y 94 de la Constitución Política de Colombia, y de los principios rectores del sistema penal, su imperatividad alcanza a cubrirse con el Bloque de Constitucionalidad.

En fin, las normas de soft law deben ser reconocidas con el alcance que les otorga la incorporación automática del artículo 4 de la Ley 1709 de 2014, y con el alcance de principio rector, de conformidad con lo dispuesto en el artículo 13 del Código Penal, como objeto que hace parte del control de convencionalidad.

\footnotetext{
internas y la Convención Americana, evidentemente en el marco de sus respectivas competencias y de las regulaciones procesales correspondientes y en esta tarea deben tener en cuenta no solamente el tratado, sino también la interpretación que del mismo ha hecho la Corte Interamericana, intérprete última de la Convención Americana. Cfr. Caso Almonacid Arellano y otros Vs. Chile. Excepciones Preliminares, Fondo, Reparaciones y Costas. Sentencia del 26 de septiembre de 2006. Serie C 154, párrafo 124; Caso Gomes Lund y otros (Guerrilha do Araguaia) Vs. Brasil. Excepciones Preliminares, Fondo, Reparaciones y Costas. Sentencia del 24 de noviembre de 2010. Serie C 219, párrafo 176, y Caso Cabrera García y Montiel Flores Vs. México. Excepción Preliminar, Fondo, Reparaciones y Costas. Sentencia del 26 de noviembre de 2010. Serie C 220, párrafo 225. Véase asimismo Caso Gelman Vs. Uruguay. Fondo y Reparaciones. Sentencia del 24 de febrero de 2011. Serie C 221, párrafo 193 .
} 
Es más, al incorporarlas en la legislación interna por la vía de un concepto jurídico indeterminado pero determinable, como ha sido planteado, se tratará de una norma en blanco de favorabilidad, contracara de las normas en blanco desfavorables -tipos penales en blanco- a los Derechos Humanos. Si existen estas, con mayor razón existen aquellas, salvo que pretenda desconocerse el principio pro homine o pro libertate.

\section{BIBLIOGRAFÍA}

Amnistía InTERnaCiOnAL (2014). Juicios Justos. Manual de Amnistía Internacional. 2. ${ }^{\mathrm{a}}$ ed. Madrid: EDAI.

BREWER-CARÍAS, Allan R. (2013). "El control de convencionalidad, con particular referencia a la garantía del derecho a la protección judicial mediante un recurso sencillo, rápido y efectivo de amparo de los derechos humanos", en Control de Convencionalidad y responsabilidad del Estado. Bogotá: Universidad Externado de Colombia, pp.

DicCiOnARIO Jurídico EsPasa (2001). Madrid: Espasa Calpe.

FAJARdo Arturo, Luis Andrés (2016). "Estándares internacionales en materia de Justicia Transicional aplicables a Colombia”, en CARlos Bernal Pulido, GERARdo Barbosa Castillo y Andrés Ciro Gómez (eds.). Justicia Transicional: el caso de Colombia. Bogotá: Universidad Externado de Colombia, pp.

Gómez Pavajeau, Carlos Arturo (2013). “Interpretación y aplicación de normas internacionales sobre Derechos Humanos en materias penal y disciplinaria”, en $R e$ vista Derecho Penal y Criminología, Vol. 34, n. ${ }^{\circ}$ 96, enero-junio de 2013. Bogotá: Universidad Externado de Colombia, pp.

Gómez Pavajeau, Carlos Arturo (2013). "Principios y normas rectoras", en Aspectos liberales y sociales del Derecho Penal. Bogotá: Ediciones Nueva Jurídica, pp. 55-82.

Gómez Pavajeau, Carlos Arturo (2014). La lucha por los derechos en el derecho disciplinario. Bogotá: Ediciones Nueva Jurídica.

Gómez Pavajeau, Carlos Arturo y Del Villar Delgado, Danilo (2014). Estándares Internacionales Vinculantes que Rigen la Detención Preventiva. Bogotá: Defensoría del Pueblo.

Hernández Castaño, DiAna PATRICIA (2014). Legitimidad democrática de la Corte Interamericana de Derechos Humanos en el control de convencionalidad. Bogotá: Universidad Externado de Colombia. 
MirAnda Bonilla, HaideER (2016). Entre constitucionalidad y convencionalidad. Bogotá: Ediciones Nueva Jurídica.

Quinche Ramírez, Manuel Fernando (2014). El Control de Convencionalidad. Bogotá: Editorial Temis.

Sandoval Huertas, Emiro (1994). Sistema penal y criminología crítica. Santa Fe de Bogotá: Temis. 